\title{
The Study of Metabolic Syndrome in Obese Persons
}

\author{
Shree Vashista ${ }^{1}, \mathrm{~V} \mathrm{~K} \mathrm{Goel}^{2}$, Ritesh $\mathrm{Lal}^{3}$ \\ ${ }^{1}$ Post Graduate Student, Subharti Medical College, Meerut. \\ ${ }_{2}^{2}$ professor, Subharti Medical College, Meerut. \\ ${ }^{3}$ Assistant professor, Subharti Medical College, Meerut.
}

\begin{abstract}
:
Background: The metabolic syndrome is a constellation of risk factors of metabolic origin that are accompanied by increased risk for cardiovascular disease and type 2 diabetes. The two major underlying risk factors for the metabolic syndrome are obesity and insulin resistance; exacerbating factors are physical inactivity, advancing age, and endocrine and genetic factors. The condition is progressive, beginning with borderline risk factors that exactly progress to categorical risk factors.

Indians have a characteristic obesity phenotype, they have relatively low BMI with abdominal obesity. Fat distributed in the abdominal region is more metabolically significant than other fat depots. Various studies shows that increased abdominal(visceral) fat accumulation is an independent risk factor for CAD, hypertension, stroke, and type 2 diabetes there b leading to metabolic syndrome. However there is paucity of data and studies regarding the relationship between abdominal obesity and metabolic syndrome in our part of country.

Aim : The aim of this study was to study the relationship between abdominal obesity and metabolic syndrome.

Materials And Method: A total of 100 patients with abdominal obesity (waist circumference $>102 \mathrm{~cm}$ in males.> $88.0 \mathrm{~cm}$ in females) were enrolled for this study between July-2014 to June-2016 are included in the study.

Results: Of the total 100 subjects, 57 males and 43 females, $71 \%$ had MS. 68\% had systolic BP>135mmhg, $52 \%$ had diastolic BP> $85 \mathrm{mmhg}, 68 \%$ were on anti hypertensive drugs, $20 \%$ were on insulin treatment, $20 \%$ were on oral hypoglycemic. $91 \%$ had fbs more than $100 \mathrm{mg} / \mathrm{dl}$. The mean level of total cholesterol, $L D L$ cholesterol, triglyceride is increased whereas the mean level of anti-atherogenic HDL cholesterol is low in subjects with $M S$

Prevalence of MS significantly high in older age groups. Age is positively associated, alcohol use is negatively associated, HDL(decreasing) and triglycerides are positively associated with the incidence of metabolic syndrome, patients of diabetic treatment are more likely to develop metabolic syndrome, Waist circumference is the better predictor of MS when compared to BMI independently.
\end{abstract}

\section{Introduction}

The Metabolic syndrome has become one of the major public health challenges worldwide ${ }^{1}$. There has been growing interest in this constellation of closely related cardiovascular risk factors.

A diagnostic of metabolic syndrome can be made if a person has there of the following five features ${ }^{2}$.

- Increased waist circumference $(102 \mathrm{~cm}$ in men and $88 \mathrm{~cm}$ in women).

- Elevated triglycerides $(150 \mathrm{mg} / \mathrm{dl})$

- Reduced HDL cholesterol $(40 \mathrm{mg} / \mathrm{dl}$ in men and $50 \mathrm{mg} / \mathrm{dl}$ in women).

- Elevated blood pressure $(130 / 85 \mathrm{~mm}$ hg or treatment for hypertension).

- Elevated fasting glucose $(100 \mathrm{mg} / \mathrm{dl})$.

When the waist circumference is $102 \mathrm{~cm}$ or more in men or $88 \mathrm{~cm}$ or more in women, the term abdominal obesity can be applied. Various definitions and diagnostic criteria are available but Asian Indians have an increased predisposition not only to diabetes ${ }^{4}$ but also to premature coronary artery disease ${ }^{3}$. This has been attributed to the so called 'Asian Indian Phenotype ${ }^{4,5}$ characterized by less of generalized obesity as measured by body mass index (BMI) but greater central body obesity as shown by greater waist circumference (WC) and waist-to-hip ratios (WHR) ${ }^{4,5}$. Thus many Asian Indians fit into the category of metabolically obese, normal weight individuals.

\section{Materials And Methods}

Prospective study of 100 cases (out patients and in patients) with increased abdominal waist circumference were enrolled in the study. Every patient was evaluated by detailed history, clinical examination, weight, height, abdominal circumference and these patients were undergone investigations like lipid profile, fbs, 
ppbs, ECG etc. Patients with waist circumference $>102 \mathrm{~cm}$ in men and $>88 \mathrm{~cm}$ in women,Serum triglycerides $>150 \mathrm{mg} / \mathrm{dl}$,HDL cholesterol $<40 \mathrm{mg} / \mathrm{dl}$ in men and $<35$ in women, Blood pressure $>130 / 85 \mathrm{mmHg}$, Serum glucose $>100 \mathrm{mg} / \mathrm{dl}$ were all included in the study. Patients with other causes of abdominal distention /obesity such as conditions like hypothyroidism, paralytic ileus, ascites were excluded from the study.

\section{Results}

1. Total 100 subjects, 57 males and 43 females.

2. The mean age in males and females are $50.91 \pm 12.96$ yrs and $52.12 \pm 14.99$ yrs respectively

3. The mean waist circumference in males and females are $107.18 \pm 10.54 \mathrm{~cm}$ and $98.99 \pm 6.84 \mathrm{~cm}$ respectively

4. The mean BMI in male group was $27.91 \pm 3.97 \mathrm{~kg} / \mathrm{m}^{2}$ and that of female group was $25.97 \pm 8.14 \mathrm{~kg} / \mathrm{m}^{2}$.

5. The mean systolic BP in male group was $139.54 \pm 23.62$ and that of female group was $138.28 \pm 21.59 \mathrm{~mm}$ $\mathrm{Hg}$.

6. The mean diastolic $\mathrm{BP}$ in male group was $86.91 \pm 13.15$ and that of female group was $85.12 \pm 12.88 \mathrm{~mm} \mathrm{Hg}$

a) $68 \%$ had systolic $\mathrm{BP}>135 \mathrm{mmHg}$.

b) $52 \%$ had diastolic $\mathrm{BP}>85 \mathrm{mug}$.

c) $68 \%$ were on anti hypertensive drugs.

7. The mean FBS in male group was $152.49 \pm 46.54 \mathrm{mg} / \mathrm{dl}$ and that of female group was $150.51 \pm 61.84 \mathrm{mg} / \mathrm{dl}$ and that of female group was $150.51 \pm 61.84 \mathrm{mg} / \mathrm{dl}$ irrespective of the treatment status.

8. The mean PPBS in male group was $205.96 \pm 74.66 \mathrm{mg} / \mathrm{dl}$ and that of female group was $188.21 \pm 73.40 \mathrm{mg} / \mathrm{dl}$ irrespective of the treatment status

a) $20 \%$ were on insulin treatment

b) $20 \%$ were on oral hypoglycemics

c) $91 \%$ had FBS more than $100 \mathrm{mg} / \mathrm{dl}$.

9. The mean total cholesterol in male group was $206.96 \pm 47.25 \mathrm{mg} / \mathrm{dl}$ and that of female group was $224.60 \pm 62.37 \mathrm{mg} / \mathrm{dl}]$

10. The mean LDL in male group was $124.79 \pm 40.80 \mathrm{mg} / \mathrm{dl}$ and that of female group was $137.53 \pm 55.99 \mathrm{mg} / \mathrm{dl}$

11. The mean HDL in male group was $38.11 \pm 5.30 \mathrm{mg} / \mathrm{dl}$ and that of female group was $42.30 \pm 23.17 \mathrm{mg} / \mathrm{dl}$

12. The mean total cholesterol in male group was $206.96 \pm 47.25 \mathrm{mg} / \mathrm{dl}$ and that of female group was $224.60 \pm 62.37 \mathrm{mg} / \mathrm{dl}$.

a) The mean level of total cholesterol, LDL cholesterol, triglyceride is increased whereas the mean level of anti-atherogenic HDL cholesterol is low in subjects with MS

13. Prevalence of MS significantly less in lower age groups (particularly in 20-30 years)

14. Age is positively associated, alcohol use is negatively associated, HDL(decreasing) and TGL are positively associated with the incidence of metabolic syndrome.

15. Waist circumference is the better predictor of MS when compared to BMI independently.

\section{References}

[1]. Deckle RH, Grundy SM, Zimmer PZ. The Metabolic syndrome. Lancet 2005; 365:1415-28

[2]. National Cholesterol Education Program (NCEP) Expert Panel on Detection, Evaluation and Treatment of High Blood Cholesterol in Adults (Adults Treatment Panel III) 2002 Third Report of the National Cholesterol Education Program (NCEP) Expert Panel on Detection, Evaluation and Treatment of High Blood Cholesterol in Adults (Adults Treatment Panel III) final report Circulation 106:3143-3421

[3]. Reddy KS, Yusuf S. Emerging Epidemic of Cardiovascular Disease in Developing Countries. Circulation 1998;97:596-601

[4]. Joshi R. MS - Emerging clusters of the Indian Phenotype. J Assoc Physicians India 2003;51:445-6

[5]. Deepa R, Sandeep S, Mohan V. Abdominal obesity, visceral fat and type 2 diabetes - 'Asian Indian phenotype'. In : Mohan V, Gundu Rao, eds Type 2 diabetes in South Asians; Epidemiology, risk factors and prevention. Jaypee Brothers Medical publishers, $2006 ; 138-52$. 